\title{
Deborah Britzman e a educação sexual: entre a pedagogia queer e a psicanálise
}

\author{
Deborah Britzman and sex education: between queer pedagogy and \\ psychoanalysis
}

\section{Deborah Britzman y la educación sexual: entre la pedagogía queer y el psicoanálisis}

\section{Gelberton Vieira Rodrigues $^{\mathrm{a}} \mathbb{D}^{\mathrm{D}}$; Patricia Porchat ${ }^{\mathrm{b}}$}

${ }^{a}$ Mestre em Educação Sexual pela Universidade Estadual Paulista (UNESP/Araraquara). Professor adjunto da UNIP/Sorocaba. Coordenador do Núcleo Sexualidade e Gênero do Conselho Regional de Psicologia-06. Universidade Paulista, Sorocaba, SP, Brasil - E-mail: gelbertonrodrigues@gmail.com

${ }^{\text {b }}$ Professora Assistente Doutora no Departamento de Psicologia da Faculdade de Ciências (UNESP/Bauru) e no Programa de Pósgraduação em Educação Sexual (UNESP/Araraquara). Universidade Estadual Paulista Júlio de Mesquita Filho, Bauru, SP, Brasil E-mail: patricia.porchat@unesp.br

Resumo: Ao articular os estudos queer com a psicanálise e com a educação, encontramos a teoria de Deborah Britzman na construção de uma educação sexual que não esteja associada com a previsibilidade e com a estabilidade. Para compreender a pedagogia queer como um campo pedagógico que subverte o discurso ideal da educação, apresentamos os estudos queer e seus pressupostos epistemológicos. Coloca-se em xeque a estabilidade das identidades e dos saberes, através da recusa intencional da identidade normalizada que produz anormalidades. Questiona-se o porquê e o quê ensinar, as "normalidades inquestionáveis" que estão associadas aos conteúdos, métodos, hierarquias e identidades escolares. A proposta pedagógica de Britzman apostará na arte, na literatura, nos jogos, nos filmes, nas brincadeiras, nos depoimentos em primeira pessoa, nas músicas e nas conversas livres e não-hierárquicas. Sugere-se que esta pode ser uma metodologia profícua para a superação das resistências à criatividade e à educação sexual.

Palavras-chave: Educação sexual. Pedagogia queer. Psicanálise. Identidade. Deborah Britzman.

Abstract: When articulating Queer studies with psychoanalysis and education, we find Deborah Britzman's theory on the construction of a sex education that is not associated with predictability and stability. To understand queer pedagogy as a pedagogical field that subverts the ideal discourse of education, we present queer studies and their epistemological assumptions. Stability of identities and knowledge is checked with the intentional refusal of normalized identity that produces abnormalities. The questions are why and what to teach, the "unquestionable normalities" that are associated with content, methods, hierarchies and school identities. Britzman's pedagogical proposal will focus on art, literature, games, movies, games, first-person testimonials, songs and free and non-hierarchical conversations. It is suggested that this can be a useful methodology for overcoming resistance to creativity and sex education.

Keywords: Sex education. Queer pedagogy. Psychoanalysis. Identity. Deborah Brizman.

Resumen: Al articular los estudios Queer con el psicoanálisis y la educación, encontramos la teoría de Deborah Britzman en la construcción de una educación sexual que no está asociada con la previsibilidad y la estabilidad. Para entender la obra, forneça um link para a licença, e indicar se foram feitas alterações. 
pedagogía queer como un campo pedagógico que subvierte el discurso ideal de la educación, presentamos estudios queer y sus suposiciones epistemológicas. La estabilidad de las identidades y los conocimientos se comprueban a través de la negativa intencional de la identidad normalizada que produce anomalías. Las preguntas son por qué y qué enseñar, las "normalidades incuestionables" que están asociadas con el contenido, los métodos, las jerarquías y las identidades escolares. La propuesta pedagógica de Britzman se centrará en el arte, la literatura, los juegos, las películas, los testimonios en primera persona, las canciones y las conversaciones libres y no jerárquicas. Se sugiere que esta puede ser una metodología útil para superar la resistencia a la creatividad y la educación sexual.

Palabras clave: Educación sexual. Pedagogía queer. Psicoanálisis. Identidad. Deborah Brizman.

Como citar o artigo:

RODRIGUES, G. V; PORCHAT, P. Deborah Britzman e a educação sexual: entre a pedagogia queer e a psicanálise.

Revista de Ciências Humanas, v.52, 2018. DOI: 10.5007/2178-4582.2018.56716

\section{INTRODUÇÃO}

Ao articular os estudos queer com a psicanálise e com a educação, encontramos a teoria de Deborah Britzman na contramão de uma recorrente radicalização da constatação freudiana de que educar seria uma "profissão impossível", ao lado das atividades de governar e psicanalisar (Freud, 1937/2006). Entre os discípulos de Freud, esta ideia é representada sobretudo pelo livro "Freud Antipedagogo" de Millot (2001), em que a autora conclui que "o conhecimento que a psicanálise provê ao educador lhe permite apenas avaliar os limites e seu poder" (p. 87).

Millot (2001) aponta que a educação se afasta da psicanálise justamente na medida que, diferentemente do que é feito em uma análise, no educar há sempre um projeto que se baseia de saída em um Ideal de Eu que enrijece as defesas narcísicas dos estudantes e, desta forma, impulsiona o trabalho das resistências e aliena o sujeito em relação a seu inconsciente. Desse modo, ela argumenta em favor da tese de que não há educação que possa articular-se à psicanálise devido à necessidade de a previsibilidade da educação sempre basear-se em um ideal de sujeito. Segundo Millot (2001, p.137): “A pedagogia se dirige ao Eu e visa a fortalecê-lo, se necessário pela angústia, a fim de submeter-lhes as pulsões. É por isto que só pode culminar na produção do recalque. A análise, pelo contrário, se apoia no Inconsciente para obter a suspensão deste"

Frente a esta argumentação e tomando a educação sexual como nosso foco de análise, questionamos: esta pedagogia precisa mesmo sempre agir sugestivamente sobre o narcisismo dos sujeitos escolares elegendo para tal "sujeitos ideais"? Ela deve sempre associar-se com a previsibilidade e com a estabilidade ou somos nós, educadores e educadoras, que já estamos viciados a lê-la desta forma? Não há no campo da educação outros fins possíveis para as pulsões que não o da repressão? Ao que nos parece, uma pedagogia aos modos sugeridos por Britzman (1995, 1995/1996, 1998, 2006) põe em questão o postulado de Millot (2011) sobre o “impossível” do educar. 
Talvez, ainda pensando a pedagogia como ela tem sido tradicionalmente concebida - como produtora de resultados previamente estabelecidos e previsíveis - a educação e a educação sexual continuem de fato sendo "impossíveis". Mas é em uma modalidade muito específica de educação que Britzman parece encontrar campo frutífero para contornar o "impossível" da educação apontado por Freud, um campo capaz de desmistificar a função fundamentalmente enganadora dos ideais educativos, e que Britzman chama de “pedagogia queer". No esteio desta pedagogia e com uma postura crítica a certas análises psicanalíticas e anarquistas da educação que só a enxergam como campo disciplinar, repressor e de controle, Britzman pensa que, quando a pedagogia e seus sujeitos estão interessados em arriscar a si mesmos:

De fato, a educação pode ser mais do que a colonização, mais do que o impulso para inventar - por meio de suas tecnologias de correção - o estudante carente, o indivíduo perigoso, o déficit de atenção, os pais ignorantes, o corpo dócil, o gênero disfuncional e todos os outros papéis trágicos que brotam do pânico moral que organiza a educação (BRITZMAN, 1998, p. 58). Trad. nossa.

Em linhas gerais, podemos dizer que Britzman localiza a saída para esta compreensão exclusivamente disciplinar da educação no encontro deste campo com a arte e com a literatura: ou seja, no encontro com pedagogias culturais em que a fantasia, a proliferação de identificações e o prazer imperam.

Mas antes de apresentar esta pedagogia queer de Britzman como um campo pedagógico que subverte o discurso ideal da educação com suas “estranhas” proposições, se faz necessário dar um passo atrás para a realização de uma apresentação dos estudos queer e de seus pressupostos epistemológicos que, poderemos perceber, em diversos pontos se relacionam com a psicanálise. A pedagogia queer e a psicanálise são as bases para a proposta de uma educação sexual, tal como pensa Deborah Britzman.

\section{OS ESTUDOS QUEER}

O conjunto de trabalhos que recebe o nome de Teoria Queer vem problematizando estratégias de normalização da sexualidade e do desejo na organização das relações sociais desde o fim da década de oitenta. Esses trabalhos buscaram inicialmente subverter e desconstruir estratégias discursivas que produzem sujeitos ditos "anormais", "doentes" "perversos" e "ilegítimos" através de pioneiros estudos literários, como os de Sedgwick (1990; 1994), que explicitavam a imbricada e constitutiva relação entre o "normal" e o "desviante" e entre as historicamente recentes identidades "heterossexual" e "homossexual". A implicação política desta teoria com as experiências de injúria e de estigmatização vividas por sujeitos socialmente lidos como "diferentes" é evidente na postura de 
contestação às desigualdades e injustiças sociais às quais esses sujeitos são submetidos por meio do questionamento das fronteiras supostamente "estáveis" que fazem valer essa diferenciação.

Nas experiências escolares de ensino básico no Brasil, identificamos diversas estratégias linguísticas utilizadas para diferenciar e submeter sujeitos socialmente marcados como inferiores: "veados", "bichas", "gordas", "mulherzinhas", "feias", "pobres" e "pretos". Estas seriam apenas algumas das maneiras de se referir aos outros que são enunciadas para associá-los à experiência da diferença que é marcada pela inferioridade, pela vergonha e pela ilegitimidade. A demarcação dessa diferença esconde, em sua enunciação, a valorização implícita dos polos opostos dos quais elas diferem e que, ao mesmo tempo, constituem: "héteros", "magras", "homens", "bonitas", "ricos" e "brancos".

Pode-se dizer que há diversas formas de se compreender as diferenças, mas, quando se trata de desigualdades e injustiças sociais, são os sujeitos (não por acaso) considerados "minorias" os que são marcados pela diferença: mulheres, negros, gays, lésbicas, travestis, transexuais, etc. Segundo Miskolci (2009):

\begin{abstract}
O termo "minoria", sob a pretensa neutralidade numérica, desvaloriza grupos subordinados pelos hegemônicos (propositalmente confundidos com maioria). Um exemplo claro é a incoerência de se referir às mulheres como minoria já que elas constituem numericamente a maior parte da humanidade. No que concerne aos estudos sobre minorias sexuais, na perspectiva queer eles, ao se denominarem desta forma, terminam por reverenciar as "maiorias" que permanecem intocadas pelo impulso desnaturalizante que colocaria em xeque sua hegemonia como padrão social pressuposto (MISKOLCI, 2009, p. 168).
\end{abstract}

No esteio da contestação daquilo que é negado pela hegemonia social, os aspectos relacionados aos processos de produção da "diferença" e da "normalidade" são o principal foco de análise dos estudos queer, que emergem como uma reação às teorias iluministas sobre o sujeito e às teorias identitárias e assimilacionistas do "movimento homossexual". Mais especificamente, os estudos queer são produzidos sob influência de determinada corrente estadunidense dos estudos culturais $^{1}$ e do pós-estruturalismo francês representado sobretudo por Michel Foucault e Jacques Derrida.

O uso da palavra "queer" para nomear este conjunto de estudos busca justamente dar ênfase a esta perspectiva política de contestação ao "hegemônico" e à "normatividade" em que estes estudos se implicam, visto que esta é uma palavra utilizada desde o século XVI na língua inglesa para se referir ao "estranho" e, mais recentemente, usada sobretudo para se referir aos sujeitos que não correspondem aos padrões sociais de gênero. Conforme Ochoa (2004, apud PELÚCIO, 2014, p. 3), queer "é como te chamam na escola quando querem te zoar". Desse modo, a opção pelo uso desta

\footnotetext{
${ }^{1}$ Segundo Miskolci (2007; 2009), destacam-se os trabalhos de Eve K. Sedgwick (1985; 1990), David Halperin (1995), Judith Butler (2003; 1993/2002), Michael Warner (1993) e Steven Seidman (1996).
} 
palavra historicamente usada como uma ofensa é feita na busca de uma ressignificação subversiva de seu uso e do questionamento do processo de diferenciação que dá a ela o peso de um xingamento ${ }^{2}$.

No dicionário Oxford (2010) da língua inglesa, queer é definido como um adjetivo, como um substantivo e como um verbo. Ou seja, é um conceito híbrido que, nas palavras de Spargo (1999/2006, p. 8), "se define contra o 'normal' ou normalizador". No referido dicionário, quando adjetivo, queer se refere ao estranho e ao não-usual, um xingamento. Em sua descrição como um substantivo, é definido como uma palavra ofensiva que se refere a um "homossexual". Como um verbo, encontramos queer em uma definição associada ao verbo “estragar” ou, literalmente, "tornar queer".

O queer, aproximando-se da desessencialização do sujeito realizada pela psicanálise e reconhecendo o postulado pós-estruturalista de que as identidades são produzidas através da linguagem, e que assim como ela são fundamentalmente instáveis e inacabadas, se apresenta como uma transgressão perturbadora ao modelo identitário e aos que se afirmam sempre idênticos a si mesmos. Pode-se, aliás, dizer que o queer é uma "aparência de identidade", forjada estrategicamente mais como uma desestabilização de suposições sobre o ser e fazer sexual do que como uma nova categoria de identidade. Deste modo, a teoria queer, ainda que com uma visão bastante heterodoxa de teoria, se apresenta como uma teoria pós-identitária que contesta os saberes que tentam vincular práticas, desejos e identidades sociais (BRITZMAN, 1995/1996; LOURO, 2001; MISKOLCI, 2007 , 2009; SPARGO, 1999/2006).

Sem dúvidas, os movimentos sociais da década de sessenta - a segunda onda do movimento feminista, o movimento homossexual e o movimento negro - tiveram influência no posterior desdobramento de uma política queer nas décadas de oitenta e noventa. Alguns destes movimentos foram os primeiros a reivindicar, em grande escala, o aspecto político do corpo, do desejo e da sexualidade. Paradoxalmente, a luta feminista pela contracepção e por direitos iguais para mulheres e homens, dos homossexuais contra o aparato médico-legal que os patologizava e dos negros contra os saberes e práticas que os racializavam, ao mesmo tempo que abrem caminhos para a contestação de discursos hegemônicos que os assujeitavam, utilizam-se de discursos que também os vinculavam a um "sujeito" de determinada política, estereotipando a leitura de tais identidades e consequentemente criando invisibilidades neste processo (MISKOLCI, 2012).

Estes importantes movimentos, chamados de "identitários", predominantes e fragmentados por diferenças internas ainda nos dias atuais, baseiam suas estratégias em uma política de afirmação e positivação de certa identidade "comum" compartilhada por um grupo de pessoas. Compreendendo as identidades como fundadas em características inatas, ou como adquiridas, o fato era que estas

\footnotetext{
${ }^{2}$ Há de se levar em consideração que, no Brasil, o termo queer não tem esse sentido. Diferentemente do que se passou nos Estados Unidos, os estudos queer entraram no Brasil pela porta das universidades e não como expressão política vinda do movimento social.
} 
políticas identitárias muitas vezes negligenciavam a complexidade da formação de identidades coletivas e sua instabilidade inquestionável, assim como ignoravam a possibilidade de sobreposição de distintas identidades ${ }^{3}$.

Seria principalmente a emergência da aids, nos anos oitenta, que desestabilizaria as bases da "ilusão" da identidade no que diz respeito à sexualidade. A epidemia de aids, inicialmente divulgada como um "câncer gay" e como o "kaposi dos gays" (devido às marcas corporais provocadas pelo sarcoma de kaposi), intensificou a discriminação contra a comunidade gay em todo o ocidente e, concomitantemente, provocou o surgimento de redes de solidariedade não necessariamente vinculadas à identidade.

Ainda que aquilo que Foucault (2012) chamou de scientia sexualis tenha se intensificado com o advento da aids, a necessidade de revisão metodológica das práticas de prevenção e tratamento da doença acarretou um deslocamento nos discursos sobre a sexualidade que, paradoxalmente, passaram a dirigir-se menos às identidades e mais às práticas sexuais.

Por conseguinte, é justamente no contexto dos ativismos da aids que o conceito queer se desdobrará na forma em que aqui é apresentado. No ápice da epidemia da doença e frente ao descaso e ao silenciamento do governo conservador de Ronald Reagan nos Estados Unidos, grupos como o ACT UP (Aids Coalition to Unleash Power) em 1987, e o Queer Nation em 1990, emergem com estratégias políticas controversas e transgressivas para a subversão do uso de um termo até então associado apenas ao preconceito: o termo queer. Estes grupos reivindicavam sua existência denunciando que parte da população havia sido rejeitada e considerada motivo de desprezo, nojo e medo, inclusive por alguns movimentos homossexuais assimilacionistas que rejeitavam as identificações transexuais, bissexuais e sadomasoquistas (SPARGO, 1999/2006). Sendo assim, o uso do termo "queer" nestes estudos em que se busca uma auto definição, era mais relacionado à problemática da "abjeção" do que da "homossexualidade", já que os "sujeitos abjetos" são aqueles que devem ter sua legitimidade humana negada para que o ideal social de humanidade se mantenha inquestionado. (MISKOLCI, 2012).

Naquele momento, na contramão de um movimento homossexual surgido na década de sessenta e preocupado com aceitação e incorporação normativa ao social, o movimento queer focava sua atuação na crítica às exigências e aos discursos autoritários e preconceituosos que instituíam as normas sociais, criticando ideais produtores de repressão, de negações e de preconceitos. Contra o discurso assimilacionista aos ideais hegemônicos de normalidade utilizado pelo movimento

\footnotetext{
${ }^{3}$ Neste ponto, é importante destacar, com Miskolci (2007a), que “o papel do queer não é desqualificar os movimentos identitários, antes apontar as armadilhas do hegemônico em que se inserem e permitir alianças estratégicas entre os movimentos que apontem como objetivo comum a crítica e contestação dos regimes normalizadores que criam tanto as identidades como sua posição subordinada no social" (p. 14-15).
} 
homossexual - "também somos normais", “também amamos", “também constituímos famílias", "também podemos ser como os heterossexuais" - o movimento queer recusa os ideais morais violentos que idealizam a heterossexualidade e que fazem valer as fronteiras da abjeção da homossexualidade (LOURO, 2001; MISKOLCI, 2012; SPARGO, 1999/2006).

Louro (2004), ao tentar definir o queer sem amarrá-lo a uma identidade fixa, utiliza a metáfora da viagem com suas ideias de deslocamento, desenraizamento e trânsito para "supor que o sujeito que viaja é, ele próprio, dividido, fragmentado e cambiante" (p. 13). Em relação a esta compreensão de sujeito, Pinar (1998) apresenta o problema de que, apesar desta compreensão "pós-moderna" de identidade ser mais "sofisticada" e mais "verdadeira" do que compreensões essencialistas, há um "preço a pagar” por esse deslocamento: “Quando abandonamos posições essencialistas, perdemos um grau de consenso e mobilização" (PINAR, 1998, p. 5).

Dentre as condições de surgimento da teoria queer, identificamos que a teoria psicanalítica se encontra presente. Seu descentramento do sujeito cartesiano do iluminismo, suposto conhecedor de si mesmo, é de relevância inegável para o pensamento queer ${ }^{4}$. Já no início do século XX, Freud e suas formulações sobre a existência de conteúdos inconscientes, não acessíveis pelo campo da consciência e da razão, abalam o ideal de sujeito racional, coerente e unificado do iluminismo (FREUD, 1900/2006, 1905/2006). Este deslocamento da concepção subjetiva inaugurado por Freud, é o que o leva a afirmar que "o eu não é o senhor nem mesmo em sua própria casa, devendo contentarse com escassas informações acerca do que acontece inconscientemente em sua mente" (FREUD, 1917/2006, p. 292).

Além da influência da psicanálise e de sua desestabilização das noções vigentes de sexualidade, de infância e de identidade, os estudos queer também compreendem a noção de "sujeito" a partir da filosofia de Foucault, cujo objetivo acadêmico, ao analisar o fenômeno do poder "foi criar uma história dos diferentes modos pelos quais, em nossa cultura, os seres humanos tornaram-se sujeitos" (FOUCAULT, 1995, p. 231). Em “O sujeito e o poder”, Foucault (idem) afirma que não é o poder, mas o sujeito que constitui o tema geral de sua pesquisa, apresentando três modos de objetivação que transformam os seres humanos em "sujeitos": investigações que produzem discursos que tentam atingir o estatuto de ciência generalizante e universal; o uso de práticas divisórias que objetivam sujeitos dividindo-os em seu interior e em relação aos outros; e o exercício do poder que faz com que os sujeitos se reconheçam como "sujeitos de (determinada) sexualidade".

\footnotetext{
${ }^{4}$ Costa (1995), ao abordar a questão da compreensão da normalidade em Freud, ressalta que, apesar deste autor usar muito o conceito e pouco explicá-lo em seus escritos, nas poucas vezes em que definiu "normalidade" relacionou-a não a um modelo a ser buscado, mas às exigências culturais. Em sua interpretação, a psicanálise ajuda a abandonar o conceito de normalidade como entendido no senso comum. Para Freud, somos todos mais ou menos bem arranjáveis e a normalidade está mais próxima da "anormalidade" do que se imagina.
} 
Com Foucault, evidencia-se que os mecanismos de sujeição e de produção de subjetividades não podem ser estudados fora de sua relação com os mecanismos de saber, de exploração e de idealização, pois são absolutamente indissociáveis. Apoiados nessa perspectiva, os estudos queer não têm a pretensão de descobrir ou apresentar "o sujeito em si mesmo", outrossim o de recusar o que as práticas de saber/poder afirmam que "ele é", isto é, liberar os sujeitos tanto das normas e dos ideais quanto dos tipos mesmo de individualização que são produtos destes. Objetivam, portanto, desnaturalizar as identidades.

Rejeitando a "hipótese repressiva" - a compreensão do poder como um grande agente repressor de uma suposta identidade que reside no âmago dos sujeitos e que poderia ser "libertada" e "conhecida" com o fim da repressão - os estudos queer compreendem o poder mais em sua característica disciplinar e produtiva do que repressora. Para eles, assim como na filosofia foucaultiana, não há um grande possuidor de poder que o exerceria sobre os outros, mas há "micropoderes" que são exercidos em muitas e variadas direções e que atravessam "capilarmente" toda a sociedade.

Com esta perspectiva analítica, desloca-se a compreensão de um "poder" fundamental que se exerce de cima para baixo e do qual devemos nos libertar, como nas análises marxistas, e torna-se central então pensar nas relações de poder como um exercício que se constitui por "disposições", "técnicas" e "manobras", que por sua vez são "contestadas", "respondidas", "absorvidas", "aceitas" ou "transformadas" e às quais se "resiste".

\section{O QUEER E A EDUCAÇÃO SEXUAL}

Os estudos queer, na medida em que se inserem na proposta foucaultiana de sabotagem do projeto de sujeito moderno, podem servir como uma estratégia potente para a superação da negação decorrente de uma paixão pela identidade, característica de certa educação sexual. Isso colocaria em xeque as coerências e estabilidades dos modelos, ainda que críticos, que fornecem quadros ideais, compreensíveis e padronizados da sexualidade e de identidades sexuais. Na esteira dessas reflexões foucaultianas, Britzman argumenta que:

Nenhuma identidade sexual — mesmo a mais normativa — é automática, autêntica, facilmente assumida; nenhuma identidade sexual existe sem negociação ou construção. Não existe, de um lado, uma identidade heterossexual lá fora, pronta, acabada, esperando para ser assumida e, de outro, uma identidade homossexual instável, que deve se virar sozinha. Em vez disso, toda identidade sexual é um constructo instável, mutável e volátil, uma relação social contraditória e não finalizada (BRITZMAN, 1995/1996, p. 74, grifos da autora). 
Ou seja, aqui Britzman compreende tanto a sexualidade normativa quanto as disparatadas como produções dentro de um campo específico de linguagem. Um campo que Warner (1993), teórico social e autor da primeira coletânea de estudos queer - "Fear of a queer planet" - chamou de "heteronormativo" ao desvelar como as relações heterossexuais são vistas na contemporaneidade como a norma, enquanto todas as outras formas de relações sexuais são vistas como desvios dessa norma. Britzman (1998), na esteira de Warner (1993), defende o uso da ferramenta analítica "heteronormatividade" ao argumentar que precisamos ir além do termo humanista "homofobia", que, de acordo com ela, além de nos remeter a um "medo individual" dos homossexuais, não contém a crítica social de como a heterossexualidade é produzida socialmente como a "norma", como a sexualidade "normal".

Segundo Britzman (1998), enquanto o termo "heteronormatividade" aponta para a íntima relação entre a produção da norma e do desvio constitutivo desta no campo da sexualidade, o termo "homofobia" é um termo que essencializa sujeitos ao focar em "atitudes individuais" de preconceito, idealizando desse modo um comportamento "não homofóbico". Este último deveria ser "facilmente" aceito por pessoas que, ironicamente colocando a questão, não vieram de Marte, mas daqui mesmo, onde os corpos dissidentes do ideal hegemônico de sexualidade e de gênero são submetidos ao silenciamento, à invisibilidade e ao ostracismo social, quando não "punidos" com a violência física e com a morte.

Pela ótica dos estudos queer, visualizamos, portanto, uma importante característica compartilhada pela heterossexualidade e pela homossexualidade: são ambas o resultado de estratégias linguísticas que devem ser ativa e reiteradamente reproduzidas. Ou seja, são posições de sujeito que estão sujeitas à iterabilidade da linguagem (LOURO, 1997; SILVA, 2013). No que diz respeito à nossa análise das resistências, podemos dizer que é precisamente a idealização da "heterossexualidade" que produz a repressão da "homossexualidade", e com ela a resistência à legitimidade do desejo homoerótico no outro e em si mesmo.

Segundo Foucault (1995), são os discursos que regulam, normatizam e produzem "sujeitos" e suas “verdades". Em sua teoria, o processo de veridição, de tornar algo verdadeiro, é um processo que se relaciona com os discursos, com a história e com o poder. Ao tomar como foco o processo de veridição, algumas importantes questões podem desestabilizar os discursos de verdade da educação sexual tomados como transcendentais e a-históricos: São verdades para quem? São consideradas verídicas de acordo com os interesses e objetivos de quais grupos sociais? Quais são os discursos “excluídos” pela verdade que se afirma única? Quem tem o poder de falar sobre si mesmo e quem pode falar sobre o outro? 
Na educação sexual estas questões tornam-se cruciais pois, ainda que os signos que constituem uma língua não tenham nenhum valor absoluto e não façam sentido se considerados isoladamente, o caráter performativo da linguagem é tal, que não há como deixar de se ter a "ilusão" de que um "homossexual” é um "homossexual” e que uma "mulher" é uma “mulher", por exemplo". Esta ilusão, necessária para que o signo funcione como tal, é chamada por Derrida (1973) de "metafísica da presença", aspecto da linguagem que oculta as relações de poder que atravessam o fenômeno da diferenciação. Este, por sua vez, organiza os significados em relação à sua ausência. São diferenciações de várias ordens e, como apresenta Silva (2013, p. 81), tem o poder de incluir/excluir (“estes pertencem e aqueles não"); o poder de demarcar fronteiras ("nós" e "eles"); o poder de classificar ("bons e maus", "puros e impuros", "desenvolvidos e primitivos", "racionais e irracionais") e o poder de normalizar (“nós somos normais e eles são anormais”). Nesta perspectiva, afinal, as noções de "eu” e de "outro" são simples distinções gramaticais em oposição binária.

Sob a influência dessa perspectiva, os estudos queer, ao reconhecerem o anormal como inteiramente constitutivo do normal, trabalham para se contrapor à tendência de essencialização destes termos em determinados sujeitos. Para tal, utilizam-se de um procedimento derridiano chamado desconstrução, que estrategicamente reverte, desestabiliza e desordena pares binários de interpretação linguística, mostrando que, ao fim e ao cabo, ninguém é diferente em si mesmo. $\mathrm{O}$ método da desconstrução, segundo Louro (2001), não significa destruir estes polos ou o fenômeno da classificação linguística, o que seria impossível visto sua centralidade na vida social. Outrossim, visa algo mais próximo do significado original da palavra "análise" que, etimologicamente, significa desfazer. Louro (1997) escreve que

A proposição de desconstrução das dicotomias - problematizando a constituição de cada polo, demonstrando que cada um na verdade supõe e contém o outro, evidenciando que cada polo não é uno, mas plural, mostrando que cada polo é, internamente, fraturado e dividido pode se constituir numa estratégia subversiva e fértil para o pensamento (LOURO, 1997, p. $35)$.

Desse modo, não somente a compreensão da identidade sexual toma novos rumos, como também a identidade de maneira geral. De acordo com Diana Fuss, pode-se deslocar a compreensão que temos da identidade como uma presença "em si” e passar a enxergá-la como diferença. A identidade, que contém o espectro da não-identidade "é sempre assumida ao preço da exclusão do Outro, da repressão ou do repúdio da não-identidade" (FUSS, 1989, apud SEIDMAN, 1993, p. 130).

\footnotetext{
${ }^{5} \mathrm{Na}$ teoria de Butler (2003), o conceito de performatividade deriva de sua leitura de Jacques Derrida feita à obra de John L. Austin. Segundo esta autora, na teoria dos atos de fala de Austin, levando-se em consideração que o poder opera através do discurso, se considera performativa a prática discursiva que torna realidade aquilo que nomeia, ou seja, a linguagem produz aquilo que nomeia.
} 
Em suma, podemos dizer que a teoria queer, no esteio destes postulados e vinculada a uma desafiadora proposta de desenvolver uma analítica da normalização, pode então ser entendida como uma teoria "sem-sujeito" engajada na defesa de seres humanos que vivem em condição de abjeção e de ininteligibilidade social (BUTLER, 2002, 2003; LOURO, 2001, 2004; MISKOLCI, 2009, 2012; PORCHAT, 2014; SEIDMAN, 1993). O interesse desta teoria pelos sujeitos estigmatizados por sua sexualidade, justifica-se pelo caráter desestabilizador da ordem social que estes retêm, além, é claro, da defesa política de uma inteligibilidade que questione sua condição de abjeção.

No contexto educacional, a experiência da abjeção é um importante ponto de partida para os estudos pedagógicos que se propõe a articular com o queer. Essa perspectiva nos desafia a encarar a escola, para além de um campo disciplinar por excelência, como um campo também atravessado por possibilidades de proliferação de questionamentos de formas convencionais de pensar, de conhecer, de diferenciar e de existir. É interessante notar como o queer parte justamente da problematização de idealizações sociais que geram negações e relações projetivas de várias ordens. Segundo Pinar, editor da primeira coletânea de estudos queer na educação ${ }^{6}$, para juntar o queer com a educação, nós educadoras e educadores "precisamos ensinar a nossos estudantes sua relação inextricável com aqueles que eles fantasiam como outro" (PINAR, 1998, p. 6, grifos do autor). Como fazer isso, levando-se em consideração o trabalho das resistências à diferença que constitui o (ideal de) Eu, é que se torna então uma questão fértil para refletirmos.

\section{A PEDAGOGIA QUEER}

Quem é o outro da educação? Quais são os corpos lidos como “diferentes" e "estranhos" nas salas de aula e o que faz com que sejam lidos assim? Estas talvez sejam importantes questões para se começar a pensar em possíveis articulações entre a pedagogia e os estudos queer, iniciando assim a discussão pela implicação com a condição de abjeção vivida no espaço escolar. Se, nas palavras de Bento (2008, p. 163), é “na escola que se aprende que a diferença faz diferença”, isto acontece porque historicamente a escola tem se mostrado uma instituição incapaz de lidar com a diferença e a pluralidade, funcionando como uma das principais instituições guardiãs das normas de sexualidade, de gênero e de outros marcadores sociais como os de raça, etnia, classe social, deficiências e estética corporal. Bento (2011), ao criticar uma perspectiva pedagógica de enclausuramento da diversidade em determinados grupos e da diferença em determinados sujeitos, afirma que

É um equívoco falar em "diferença ou diversidade no ambiente escolar" como se houvesse o lado da igualdade (...). Se tivermos essa premissa evidente, talvez possamos inverter a lógica:

${ }^{6}$ Cf. “Queer Theory in Education”, 1998. 
não se trata de identificar o "estranho" como "diferente", mas de pensar que estranho é ser igual (BENTO, 2011, p. 556, grifos nossos).

Ou seja, é precisamente a subsunção da diferença para o mesmo de uma perspectiva multiculturalista que a autora propõe interromper. Reproduzindo algumas das falas sobre vivências escolares cedidas por pessoas transexuais entrevistadas por ela em sua tese de doutoramento, Bento (2008) nos faz refletir sobre como o ambiente escolar pode não ser nada "fácil" para pessoas que destoam dos ideais normativos da sociedade, entre eles os de gênero e de sexualidade. Vejamos uma delas:

Marcela (nome fictício): “Meu Deus, que horror era tudo aquilo! Eu não saía para o recreio. Eu achava que esse órgão não tinha a menor importância, que todo mundo me reconhecia como uma mulher. Muitas vezes puxavam meu cabelo e eu tinha que brigar, principalmente quando me chamavam de veadinho" (BENTO, 2008, p. 167).

São comuns situações de violência na escola voltadas àqueles e àquelas que não se conformam à lógica heteronormativa de sexualidade e gênero. Muito pouco ou quase nada é dito ou feito frente a essas perturbações. O que poderia ser diferente no sentido de uma abertura para outras identificações que não exclusivamente a heteronormativa? Que efeitos poderiam ter nos sujeitos infantis outros saberes que ali nunca podem ser enunciados? Quais dúvidas, histórias, identificações e afetos "não ousam dizer seu nome" no espaço escolar?

Os estudos queer, ao se aproximarem dos discursos da educação, não apenas apontando limites, mas questionando-os e transgredindo-os, ameaçam a vocação normalizadora deste campo eminentemente disciplinar: suas identidades e saberes são postos em xeque, questiona-se o porquê e $o$ quê ensinar. O estranhamento queer da pedagogia, desta forma, torna-se incômodo porque questiona as "normalidades inquestionáveis" que estão associadas aos conteúdos, métodos, hierarquias e identidades escolares.

Britzman (1995, 1995/1996, 1998) considera que questões que dizem respeito à educação, ao conhecimento e à identidade, têm a ver com as estruturas que modelam o "pensável" em uma sociedade e que limitam o pensamento dos sujeitos, sendo, justamente por isso, questões que podem tanto fazer a diferença na pedagogia, quanto produzir resistências ao novo naqueles e naquelas que buscam manter o estatuto da normalidade.

Historicamente, através de práticas pedagógicas diversas e cambiantes, a escola tem (re)produzido sujeitos, valores e verdades em articulação com o que a hegemonia social idealiza como “normal" e "desejável" em relação a esses conceitos. Podemos inclusive afirmar que a pedagogia tradicional é a pedagogia da normalidade. Em seu livro "Documentos de identidade: uma introdução às teorias do currículo", Silva (/2013) esclarece essa afirmação ao elucidar como as teorias tradicionais de pedagogia, ao não se atentarem às teias de poder que atravessam seus discursos e 
estratégias, acabam apenas se preocupando com objetivos, procedimentos e métodos para a obtenção de resultados supostamente mensuráveis. Resultados que, no fim das contas, estão relacionados ao que deve "saber" e consequentemente "ser" um sujeito "ideal", um sujeito "normal" e, em última instância, um sujeito "desejável”.

Na opinião de Silva (2013), esta aproximação entre estudos queer e pedagogia iniciada na primeira metade da década de 1990 representa uma radicalização do questionamento da estabilidade e da fixidez da identidade na educação feito anteriormente pela teoria feminista, incorporando-a e indo além da hipótese da construção social da identidade, subvertendo e confrontando com isso "a ilusão e a prisão da identidade fixa” (p. 107).

Em relação à emergência do campo conhecido como pedagogia queer, parece haver consenso de que a primeira publicação que discute esta possibilidade aconteceu em 1993 no "Canadian Journal of Education", com o artigo de Mary K. Bryson e Suzanne de Castell intitulado "Queer Pedagogy: Praxis Makes Im/Perfect". Neste artigo as autoras tentam construir uma espécie de "queer praxis" a partir de um relato de experiências de um curso de estudos lésbicos oferecido por elas na graduação. No referido artigo, as relações entre os temas sexualidade, identidade, diferença, agência e pedagogia são exploradas em sua conexão com a lesbiandade.

Bryson e Castell (1993), tendo notado a falta de estudos sobre a educação nos chamados estudos gays e lésbicos e preocupadas com a normalização das identidades sexuais realizada pela pedagogia tradicional, são otimistas em relação a uma queerização desta área. Para elas, a pedagogia queer poderia se referir tanto à educação realizada por educadoras lésbicas e gays, quanto ao currículo e ao ambiente produzido para estudantes gays e lésbicas. Ou, então, referir-se à produção deliberada de relações queer e à produção de subjetividades como performances desviantes - "algo como uma pedagogia carnavalesca pós-moderna do submundo (...) implementada deliberadamente para interferir com e na produção da chamada normalidade dos sujeitos escolares"(BRYSON; CASTELL, 1993, pp. 298-299, grifo das autoras).

Mas se a identidade não é o que a identidade é (SILVA, 2000, p. 96), torna-se complexa a possibilidade de produção deliberada do ser. Há, além do mais, que se levar em consideração o trabalho das resistências nesta “queerização". Como as próprias Bryson e Castell (1993) destacam, a “identidade não é algo escolhido livremente ou 'naturalmente' emergente, mas criada em reação, em defesa, pela diferença e pela oposição" (BRYSON; CASTELL, 1993, p. 294, grifos nossos).

Parece que, ao se estabelecer a proposta de uma pedagogia queer, imediatamente nos deparamos com as questões que a própria teoria queer levanta em relação à fixidez e à estabilidade das identidades, mas, dessa vez, voltada contra si própria. Pode, afinal, uma pedagogia imaginar a si mesma como queer? É Luhmann (1998), psicanalista e teórica queer, quem problematiza se a 
pedagogia queer pode, ela mesma, resistir ao desejo de autoridade, de estabelecer conhecimentos, enfim, de produzir novas formas de assujeitamento.

Se o conhecimento está sempre associado ao poder e a produção de sujeitos, seria a pedagogia queer, então, uma pedagogia ao avesso, já que recusa a sujeição em seus dois sentidos expostos por Foucault? ${ }^{7} \mathrm{Na}$ contramão da tradicional associação imediata entre pedagogia e novos conteúdos a serem ensinados, pode a proposta queer de pedagogia subverter a lógica simplista do "ensinoaprendizagem" e questionar o próprio status de neutralidade dado ao conhecimento que supostamente deve ser aprendido? A própria Luhmann (1998) responde:

\begin{abstract}
O que está em jogo na pedagogia queer não é a aplicação da teoria queer (como um novo conhecimento) na pedagogia, tampouco a aplicação da pedagogia (como um novo método) para a disseminação de uma teoria e de um conhecimento queer. (...) O que está em jogo nesta pedagogia é a situação profundamente social ou dialógica da formação do sujeito, o processo pelo qual nós construímos a nós mesmos através e contra os outros. (...) Esta pedagogia queer encoraja uma prática ética pelo estudo dos riscos da normalização, dos limites de suas próprias práticas, e das (im)possibilidades de (subversivamente) ensinar e aprender. (LUHMAN, 1998, s/p., grifos nossos).
\end{abstract}

Como se pode constatar, os estudos queer e sua implicação com a questão da produção de identidades normativas que geram a abjeção transgridem as discussões educacionais que associam ingenuamente a pedagogia ao conhecimento tido como "científico" ao mesmo tempo que subvertem a compreensão essencialista de sujeito.

Britzman (1995), também considerada uma das precursoras do que se tem chamado de pedagogia queer, propõe no ensaio ambiguamente intitulado "Is there a Queer Pedagogy? Or, Stop reading straight ${ }^{8 "}$ " uma aproximação entre a pedagogia e a teoria queer ao enfatizar que esta última insiste em posicionar a produção da normalidade como um problema da cultura: como produtora de limites ao pensável e de fronteiras de dignidade e de inteligibilidade para as identidades. Sua tentativa neste artigo, que dialoga continuamente com a psicanálise, é a de pensar técnicas específicas da teoria queer que possam fazer repensar tanto a pedagogia quanto seus próprios conhecimentos (d)e identidades.

Para abrir espaço para pensar o “impensável” na educação, Britzman (1995) propõe o estudo dos limites, o estudo da ignorância, e o estudo das práticas de leitura. Todos estes, estritamente relacionados com o estudo das identidades, das resistências e da normalidade. Acreditando na potência transformadora que acompanha novas possibilidades de leitura e partindo da ideia de que “ler é sempre arriscar o eu” (BRITZMAN, 1995, p. 164), Britzman convida a implicarmo-nos com

\footnotetext{
${ }^{7}$ No primeiro modo, sujeito a alguém pelo controle e dependência, e no segundo, sujeito a sua própria identidade por uma "consciência de si” ou autoconhecimento (FOUCAULT, 1982/1995).

${ }^{8}$ A ambiguidade se deve ao fato de que straight, na língua inglesa, ao mesmo tempo que significa "certo", "correto" e "reto", também se refere à heterossexualidade e àqueles e àquelas que se engajam em práticas e identidades heterossexuais.
} 
uma ética pedagógica que transgrida leituras hegemônicas viciadas em identidade, contrariando os impulsos de normalizar significados do desejo e de certificar identidades estáveis e acabadas para os sujeitos. Impulsos estes, tão característicos do campo da educação, inclusive em sua perspectiva crítica.

No mesmo ano da publicação deste artigo, Britzman (1995/1996) busca tornar complexa a noção de identidade dos estudos educacionais críticos em "O que é esta coisa chamada amor? Identidade homossexual, educação e currículo" ". De acordo com este segundo texto, ainda que desde a década de 1970 as educadoras e educadores venham demonstrando preocupação em teorizar as experiências de desigualdade vividas no espaço escolar, é flagrante no contexto de sua publicação a necessidade de se atribuir à categoria "identidade" suas "caleidoscópicas qualidades" (p. 72), visto que esta não é vivida "como hierarquia, como estereótipo ou a prestações" (p. 73). Aqui, as críticas de Britzman (1995/1996) endereçadas aos estudos e pesquisas inspirados no feminismo, no estruturalismo, no marxismo e nas teorias anti-racistas leem uma limitação no alcance dessas perspectivas argumentando que nelas a noção de identidade permanece com muita frequência presa a uma visão equivocada e fragmentada de que as identidades são dadas e recebidas. Para ela, devido às construções identitárias formarem-se desde o início impregnadas de sentidos e de intenções dos outros, a categoria identidade seria melhor analisada como sendo polimórfica e polifônica.

Em certa medida, esta alteridade continua sempre presente na própria organização psíquica de cada um. Aprendemos a falar e a ler e depois não temos "controle" total do que lemos ou do que pensamos com as palavras que aprendemos. Tampouco conseguimos deliberadamente "desaprender" a ler ou a pensar. Somos constantemente interpelados por narrativas que demandam posições generificadas e racializadas, posições que marcam e são marcadas pelo desejo. Muito do que somos chamados a ler no campo social é, de fato, contraditório e inconsciente. Ainda assim, pouco espaço nos é cedido para que possamos nos questionar sobre essas contradições, que existem em todos e todas nós, para além de consultórios de psicanálise e de experiências artísticas e oníricas tais como o cinema, a literatura, a mitologia e a música: espaços onde a fantasia impera. O campo da educação, por sua vez, parece fugir das contradições e da fantasia, insistindo no linear, na ordem e no estático, baseado num sujeito racional, centrado e autônomo da Modernidade (SILVA, 2013, p. 115).

Relacionando sua crítica ao campo dos estudos tanto normativos quanto críticos da sexualidade e já evidenciando sua aposta em situações que envolvem os afetos na pedagogia, Britzman (1995/1996) comenta que é quando se tenta teorizar sobre o "sexo" que se torna evidente a dificuldade de se isolar a identidade "do frenesi e da confusão de momentos" que a tornam tão

\footnotetext{
${ }^{9}$ Quando fizermos referência a este artigo, utilizaremos (Britzman, 1995/1996) por termos utilizado a tradução realizada por Tomaz Tadeu da Silva do original "What is this thing called love?".
} 
interessante. Pois quando se trata do desejo, de amor e de afetividade, "a identidade é capaz de surpreender a si mesma: de criar formas de sociabilidade, de política e de identificação que desvinculem o eu dos discursos dominantes da biologia, da natureza e da normatividade" (p. 73).

Neste ponto, há o argumento de que a identidade, e ainda mais evidentemente a identidade sexual, é uma relação social nunca finalizada que acontece tanto no interior emocional do "eu" quanto entre "outros" seres. Em ambos os textos em que Britzman (1995, 1995/1996) apresenta sua pedagogia queer, ela lança mão do conceito de identificação, da psicanálise, para fazer a crítica de um determinismo construtivista. Propõe uma noção de identidade que, além de ser não-determinista, contraditória e dividida, pode ser sempre rearranjada, desestabilizada e transformada pela complexidade das experiências vividas com certa dose de afetos que a fazem cruzar as fronteiras dos marcadores de sexualidade, gênero, raça, classe, etnia, geração, nacionalidade, aparência física ou estilo popular.

Para a pedagogia queer, esta noção de identidade formada por identificações traz questões tais como: o que é preciso para que as práticas pedagógicas estejam eticamente engajadas com a justiça social sem estarem presas à dinâmica binária do opressor versus o oprimido? Ou ainda, elaborando a questão de outra forma e aproximando-a de nosso tema em questão: como pode a pedagogia incluir a (homo)sexualidade em seus conteúdos sem esbarrar nas estereotipadas e por vezes patéticas histórias de vitimização e de homofobia que acabam, ainda que bem-intencionadas, reproduzindo a lógica da hierarquização das identidades e, com isso, o trabalho das resistências?

A partir desta compreensão "menos ingênua" da identidade, que lê este conceito como algo que é sempre mais do que aquilo que os discursos dominantes demandam, o desafio torna-se então teorizar a diferença sem cair no terreno da sujeição/subjetificação total do "eu", sem a demarcação inerte e binária de um "nós normais" e de um "eles diversos". No encontro com este desafio, Britzman (1995) propõe sua "pedagogia queer" não como uma área confinada ao ensino por, para ou sobre “oprimidos” - afinal, a diferença não é característica apenas destes sujeitos.

Em meu trabalho na pedagogia, que quero chamar de minha pedagogia queer, estou tentando superar oposições binárias tais como o "tolerante" e o "tolerado", os "oprimidos" e "opressores" e ainda me embasar em uma análise da diferença social que possa explicar como a dinâmica da subordinação e da sujeição funcionam ao nível do histórico, do estrutural, do epistemológico, do conceitual, do social e do psíquico (BRITZMAN, 1995, p. 164-165).

Segundo Britzman (1995), sua posição político-epistemológica requer um projeto ético que comece com o engajamento da diferença como a base da sociabilidade escolar por esta ser sempre a base da produção de todas as identidades. Ainda que seja evidente a necessidade do reconhecimento de que são as identidades dissidentes das expectativas (hétero)normativas as que estão mais expostas a um regime de visibilidade policiada e a violências simbólicas e materiais na educação, Britzman 
(1995/1996, p. 82) pretende que se escape de uma "defesa afirmativa" destas identidades subalternas ao argumentar que as construções da sexualidade funcionam discursivamente para normalizar tanto aquilo que é marcado (a homossexualidade) quanto aquilo que é não-marcado (a heterossexualidade).

São elencadas duas implicações que tocam o processo de sujeição realizado na educação: uma que se relaciona ao pensar eticamente a respeito dos efeitos que discursos sobre as diferenças, escolhas e visibilidades podem ter sobre as identidades escolares; e outra que se refere ao pensar sobre como os limites pedagógicos, através das estruturas de aceitação/recusa da alteridade, podem produzir a própria concepção de "sujeito da diferença" como uma exceção, como um sujeito "fora da normalidade", como um sujeito cuja economia de afetos não parece nada propulsora de identificações e de desejos. (BRITZMAN, 1995)

Com estas problematizações, diferentemente de uma lógica que toma os "homossexuais" e os "heterossexuais" como identidades inequívocas e que desconsidera a emergência deste vocabulário em um contexto médico do século XIX, a pedagogia queer de Britzman entende que toda identidade sexual é, afinal, constantemente (re)arranjada, (des)estabilizada e (des)feita por meio de identificações que acontecem através de experiências afetivas vividas dentro e fora do espaço escolar. Por conseguinte, sua proposta pedagógica demanda que a própria "heterossexualidade" seja desvinculada dos discursos da naturalidade e da normalidade para que o significante "homossexualidade" possa ser rearticulado. Para além do reconhecimento limitado de duas possibilidades do desejo, nas palavras da autora, "a heterossexualidade deve ser vista como uma possibilidade entre muitas" (BRITZMAN, 1995/1996, p. 83).

Nesta articulação teórica, podemos argumentar que se há uma aparente "maioria heterossexual", isto não se dá pelo fato desta experiência de desejo ser representante da "normalidade" do desejo e as outras de seus "desvios". Isto se dá, deveras, porque desejo e identidade se fazem num processo de identificação que ocorre em circunstâncias e contextos que são, na maioria das vezes, hostis e violentos em relação a práticas homoafetivas, o que as torna ininteligíveis e indignas socialmente e faz com que o "desejo homossexual" deva ser negado nos outros e ser objeto de resistência em si mesmo.

Neste ponto, é importante frisar que mesmo com o preço do desestímulo social e do ostracismo, os sujeitos ainda podem se identificar e se reconhecer com o desejo homoerótico porque este também está relacionado com um prazer que excede os limites postos pelo social e pelas normas (como uma resistência da pulsão, como vimos). A questão é que para que estes sujeitos reconheçam a si mesmos como legítimos, afirma Britzman (1995/1996), “os próprios significantes 'gay' e 'lésbica' devem ser rearticulados de forma que sejam prazerosos, interessantes e eróticos” (p. 83). Somente 
após essa ressignificação linguística estes podem reivindicar identidades que em (quase) todos lugares são ensinados a repudiar e desprezar.

Quanto à "heterossexualidade", ainda que seja produzida como uma identidade "nãomarcada" nos discursos partilhados dos últimos dois séculos, há de se pontuar agora que mesmo esta experiência desejante se efetiva igualmente por uma série de violências, imperativos, proibições, coibições e omissões sobre sua própria constituição. Ou seja, mesmo pessoas que se relacionam hegemonicamente de maneira "heterossexual" e que se reconhecem nesta identidade têm seus corpos e performances de gênero constantemente vigiados para que se enquadrem nos rígidos padrões heteronormativos que garantem inteligibilidade social para o homem e para a mulher "de verdade" categorias lidas como singulares e idênticas a si mesmas.

No atual contexto de relativos avanços no que tange à visibilidade de vidas e de prazeres "nãoheterossexuais", por exemplo, é notável a existência de contínuos esforços e estratégias em manter a heterossexualidade como a identidade que é compulsória e meticulosamente transmitida como a "sexualidade normal e não-marcada". Frente a estas estratégias, pode-se questionar: caso o valor de tal identidade "heterossexual" fosse de fato transcendental e não devesse em nada à suplementariedade constituída em oposição à homossexualidade, por que haveria tanta preocupação e insistência em manter as experiências dissidentes das heteronormas longe dos currículos escolares e perto dos xingamentos, do perigo, do "pecado" e dos descréditos sociais? Justamente este "medo" da presença de identidades dissidentes no currículo escolar, apresentadas em seus próprios termos, não pode evidenciar a não "naturalidade" da heterossexualidade?

À vista dessa elaboração, a potência de uma pedagogia queer no que se refere ao "estudo dos limites" reside justamente no questionamento das próprias bases normativas e humanistas das “identidades”, e não no reforçamento desta categoria com respostas identitárias aos ataques da norma que acabam por reiterar a divisão que cria, ela mesma, o campo de batalha. Excedendo as posições essencialistas, binárias e (hétero)normativas que atravessam a leitura estereotipada das identidades e dos desejos que ainda imperam na educação escolar e nas resistências ao debate sobre sexualidade na educação escolar, Britzman (1995, 1995/1996) sugere que as identidades sexuais não precisam necessariamente estar presas a estruturas pré-estabelecidas de inteligibilidade para serem consideradas legítimas, propondo para isso uma concepção de identidade tanto como um efeito discursivo do social quanto como sendo constituída através de identificações e, portanto, de afetos.

Neste ponto, vislumbramos que a questão dos afetos e das identificações que estes possibilitam fica em primeiro plano na teoria de Britzman, para quem o "estudo da aprendizagem é inseparável do estudo do amor" (BRITZMAN, 1998, p. 31). Torna-se complexa a noção de identidade dos estudos educacionais, na medida em que, além de ser social e histórica, é concebida como também 
capaz de rearticular a si mesma a partir do desejo, do prazer e do amor (BRITZMAN, 1995/1996, 1998, 2006). Esta sua teoria se apresenta desta forma como uma afiada crítica aos métodos baseados no princípio multiculturalista da representação na educação sexual. Em síntese, é precisamente a subsunção da diferença para o mesmo que esta perspectiva pretende interromper. $\mathrm{O}$ queer, na educação, desafia a reprodução da mesmice e da indiferença no espaço escolar.

Destarte, pensar a educação, a pedagogia e a formação de professores com a noção de identificação em detrimento da empoeirada categoria de identidade, no que diz respeito a suas práticas, seus discursos, suas proposições de atividades e seus regimes de verdade, pode superar o dualismo entre os parâmetros psicologicistas e construtivistas que dominam os estudos educacionais, sem cair em determinismos tanto da esfera do social quanto do psíquico. Entendendo a identidade como um estado de necessidade situacional e apresentando a educação como um processo que sempre arrisca o "eu" dos sujeitos através de novas aprendizagens e de novas possibilidades de leituras de si e do mundo que são transmitidas pelo outro, Britzman (1995, 1995/1996, 1998) sugere que alguns riscos, de fato, podem tornar as pessoas e a pedagogia mais interessantes.

\section{A EDUCAÇÃO SEXUAL QUEER}

Se quisermos agora aproximar a educação sexual daquilo que Foucault chamou de um processo de veridição das verdades construídas na esteira da história, das comunidades e da memória afetiva de cada um, devemos então colocar tanto o "normal" quanto os estereótipos regulatórios do "diferente" em situação de estranhamento. Devemos problematizar uma pedagogia que ignora a performatividade da linguagem, das identidades e das práticas de leitura, que ignora a inconstância e as condições epistemológicas de qualquer discurso.

A proposta pedagógica de se apostar na arte, na literatura, nos jogos, nos filmes, nas brincadeiras, nos depoimentos em primeira pessoa, nas músicas e nas conversas livres e nãohierárquicas que teimam em nunca deixar de acontecer na sala de aula, pode ser então uma metodologia profícua para o árduo objetivo da superação das resistências à educação sexual. Ou seja, pode ser um potente meio na tentativa de pensar contra os próprios pensamentos. $\mathrm{O}$ uso destas estratégias literárias traz outras vozes e outros desejos para o espaço educativo, o que faz com que os educadores deixem, eles próprios, de ocupar o lugar de um Outro que sabe o que é melhor para o desejo de todos e de todas, potencializando e surpreendendo desta forma os alcances da perversidadepolimorfa de qualquer sexualidade, inclusive a dos educadores.

Com este entendimento, a pedagogia queer se propõe a engajar as e os estudantes em um diálogo sobre como e por que as posições subjetivas e identitárias são afirmadas ou recusadas, por 
exemplo, nas práticas de leitura de materiais literários ou fílmicos que abordem a temática da diferença e do preconceito. Desta forma, identificamos que o trabalho com as resistências tem tanta importância para esta pedagogia quanto têm para uma prática clínica em psicanálise.

Assim como na psicanálise há uma proposta não sugestiva de desconstrução de idealizações produtoras de sofrimento e de sintomas na clínica, na pedagogia em questão - com o evidente objetivo político de ampliar as possibilidades de leitura dos corpos para que caibam na categoria de humano - há o interesse pelo confronto e pela desconstrução das próprias práticas de leitura dos singulares sujeitos que compõem o espaço escolar, sejam eles estudantes ou professores. Deste modo, a proposta de pensar o impensável da educação está relacionada a uma perspectiva que põe em risco (ou ao menos em questão) as leituras e posições normalizadas e hierarquizadas das identidades e das relações sociais (Britzman, 1995). Podemos dizer, afinal, que o interesse maior é o de questionar, em um espaço de sociabilidade receptivo às contradições, os próprios ideais que impulsionam o trabalho das resistências.

A queerização da pedagogia abre espaço para novas, possíveis e ainda não imaginadas leituras da realidade, de si e dos outros, sendo assim uma pedagogia aberta à contemporaneidade. Afinal, se o que está em jogo nesta pedagogia são as situações dialógicas da formação do sujeito - os processos de como são produzidas as "identidades" e a "verdade" através e contra a alteridade - a questão deste campo então se aproxima da ainda contemporânea afirmação foucaultiana de que "o objetivo hoje em dia não seja descobrir o que somos, mas recusar o que somos" (FOUCAULT, 1995, p. 239).

Incorporando este desafio em seu corpus epistemológico, que se torna desta forma ele próprio uma "teoria" da recusa intencional da identidade normalizada que produz anormalidades e que tampona a criatividade com resistências, os estudos queer sugerem o questionamento e a incerteza como suas principais estratégias para a pedagogia e para o pensamento. Nesse sentido, Britzman (1995/1996), defende a criatividade dos “detours” em oposição à lógica "straight”. Provocativa e por vezes desconfortante, esta pedagogia desnaturaliza os caminhos retilíneos de se chegar a conclusões e enxerga possibilidades criativas nos desvios e devaneios, assim como, em nossa interpretação, o faz a psicanálise.

\section{REFERÊNCIAS}

BENTO, B. O que é transexualidade. São Paulo: Brasiliense, (2008).

BENTO, B. Na escola se aprende que a diferença faz a diferença. Revista Estudos Feministas, 19(2), (2011). p. 549-559. 
BRITZMAN, D. P. Is there a queer pedagogy? Or, stop reading straight. Educational theory, 45(2), (1995). p. 151-165. Recuperado em 25 de setembro, 2015 de: https://www.academia.edu/22058440

BRITZMAN, D. P. O que é esta coisa chamada amor?: identidade homossexual, educação e currículo. Educação \& Realidade, 21(1), (1995/1996), p. 71-96.

BRITZMAN, D. P. Lost subjects, contested objects: Toward a psychoanalytic inquiry of learning. New York: Suny Press, (1998).

BRITZMAN, D. P. Novel Education: Psychoanalytic studies of learning and not learning (Vol. 300). New York: Peter Lang Publishing, (2006).

BRYSON, M.;CASTELL, S de. Queer pedagogy: Praxis makes im/perfect. Canadian Journal of Education/Revue canadienne de l'éducation, (1993), p. 285-305.

BUTLER, J. Cuerpos que importan: sobre los límites materiales y discursivos del "sexo". Buenos Aires: Paidós, 2002

BUTLER, J. Problemas de gênero: feminismo e subversão da identidade. Rio de Janeiro: Civilização Brasileira, 2003

COSTA, J. F. A face e o verso: Estudos sobre o homoerotismo II. São Paulo: Escuta, 1995.

DERRIDA, J. Gramatologia. São Paulo: Perspectiva, 1973

DICIONÁRIO Oxford Advanced Learner's Dictionary. Oxford University Press. Oxford. 2010.

FOUCAULT, M. História da sexualidade I: a vontade de saber (22 impressão). Rio de Janeiro: Graal, 2012

FOUCAULT, M. O sujeito e o poder. Em: Dreyfus, H. \& Rabinow, P. (eds.) Michel Foucault, uma trajetória filosófica: para além do estruturalismo e da hermenêutica. Rio de Janeiro: Forense Universitária, 1995, p. 231-249.

FREUD, S. A psicologia dos processos oníricos, 1900. In: . A interpretação de sonhos continuação. Rio de Janeiro: Imago, 2006. (Edição Standard Brasileira das Obras Psicológicas Completas de Sigmund Freud, 5). 
FREUD, S. Três ensaios sobre a teoria da sexualidade, 1905. In: Um caso de histeria e

Três ensaios sobre a teoria da sexualidade. Rio de Janeiro: Imago, 2006. (Edição standard brasileira das obras psicológicas completas de Sigmund Freud, 7).

FREUD, S. Análise terminável e interminável, 1937 [1934-38]. In: . Moisés e o monoteísmo três ensaios. Rio de Janeiro: Imago 2006. (Edição standard brasileira das obras psicológicas completas de Sigmund Freud, 23)

FUSS, D. Essentially Speaking. New York: Routledge, 1989.

HALPERIN, D. M. Saint Foucault: A Gay Hagiography. New York: Oxford University Press, 1995.

LOURO, G. L. Gênero, sexualidade e educação: uma perspectiva pós-estruturalista. Petrópolis: Vozes, 1997.

LOURO, G. L. Teoria Queer: Uma Política Pós-Identitária para a Educação. Revista Estudos Feministas, 9(2) Florianópolis: IFCH, 2001.

LOURO, G. L. Um corpo estranho: Ensaios sobre sexualidade e teoria queer. Belo Horizonte: Autêntica, 2004.

LUHMANN, S. Queering/querying pedagogy? Or, pedagogy is a pretty queer thing. Em: Pinar, W. F. (org) Queer theory in education, 1998, p.141-155.

MILLOT, C. Freud antipedagogo. Rio de Janeiro: Jorge Zahar Ed., 2001.

MISKOLCI, R.. A Teoria Queer e a Questão das Diferenças: por uma analítica da normalização. Em: Congresso de leitura do Brasil, vol. 16, 2007, p. 1-19.

MISKOLCI, R. A Teoria Queer e a Sociologia: o desafio de uma analítica da normalização. Sociologias, 11(21), 2009.

MISKOLCI, R. Teoria Queer: um aprendizado pelas diferenças. Belo Horizonte: Autêntica, 2012.

OCHOA, M. “Ciudadanía perversa: divas, marginación y participación en la 'localización'”. En Daniel Mato (coord.), Políticas de ciudadanía y sociedad civil en tiempos de globalización. Caracas: FACES, Universidad Central de Venezuela, 2004. p. 239-256. 
PELÚCIO, L. Traduções e torções ou o que se quer dizer quando dizemos queer no Brasil? Revista Periódicus, 1(1), 2014, p. 68-91.

PINAR, W. F. Introduction. Em: . (Org.) Queer theory in education, New York: Routledge, 1998.

PORCHAT, P. Psicanálise e transexualismo: desconstruindo gêneros e patologias com Judith Butler. Curitiba: Juruá, 2014.

SEDGWICK, E. K. Between Men: English Literature and Male Homosocial Desire. New York: Columbia University Press, 1985.

SEDGWICK, E. K. Epistemology of the Closet. The lesbian and gay studies reader, 45, 1990.

SEDGWICK, E. K. Queer and Now. Em: Tendencies. London: Routledge, 1994.

SEIDMAN, S. Identity and Politics in a Postmodern Gay Culture: Some Historical and Conceptual Notes Em: Warner, M. (Ed.) Fear of a Queer Planet: Queer Politics and Social Theory, 1993.

SEIDMAN, S. Queer Theory/Sociology. Malden: Blackwell, 1996.

SILVA, T. T. da. A produção social da identidade e da diferença. In: SILVA, T. T. da (org.)

Identidade e diferença: a perspectiva dos estudos culturais. Petrópolis: Vozes, 2000, p. 73-102.

SILVA, T. T. da. Documentos de identidade: uma introdução às teorias do currículo. ed. 3. Belo Horizonte: Autêntica, 2013.

SPARGO, T. Foucault e a teoria queer (1999). Rio de Janeiro: Pazulin, 2006.

WARNER, M. Fear of a Queer Planet: queer politics and social theory. Minneapolis: University of Minnesota Press, 1993. 